\title{
El deseo latente de la imagen-spam
}

\section{Artículo de investigación}

\section{Geraldiny Guerrero Muñoz}

Universidad Complutense de Madrid, España

lamonalisager@hotmail.com

Recibido: 8 de febrero de 2021

Aceptado: 25 de abril de 2021

Como citar este artículo: Guerrero Muñoz, G. (2022)

El deseo latente de la imagen-spam. Calle14: revista de investigación en el campo del arte. 17(31), pp. 36-49. DOI: https://doi.org/10.14483/21450706.18689

El presente documento forma parte de la investigación del Trabajo Fin de Máster "El deseo latente de la imagen-spam" en el programa de Master en Investigación Arte y Creación de la Universidad Complutense de Madrid en el periodo 2019-2020.

\section{(c) (1)}

https://creativecommons.org/licenses/by/4.0/deed.es 


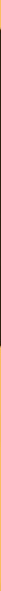

EDITORIAL VÍDEO

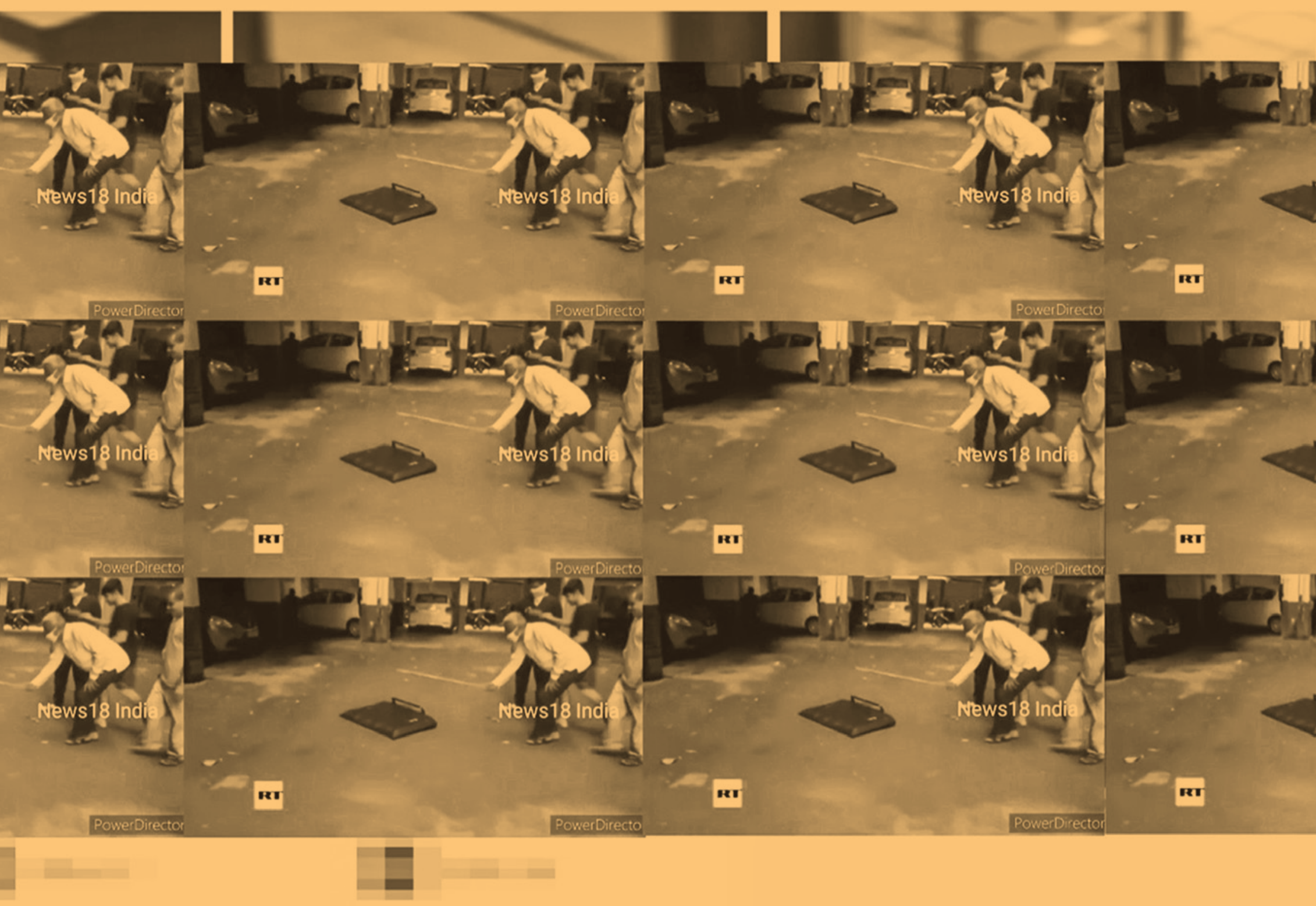

solo cosa de Maduro y su esposa o está expandida entre su entorno?

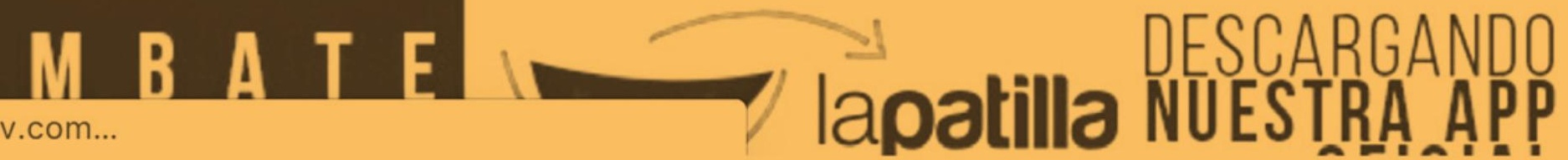
Dapossioure 


\title{
Resumen
}

En la cultura digital contemporánea el aumento exponencial de las imágenes en entornos digitales está proporcionando una experiencia desbordada en todos los campos que ofrece la conectividad a internet, sea en espacios físicos o digitales. Es por esto que nuestro enfoque es analizar los lugares y trayectorias que tienen las imágenes-spam y su propio deseo latente, visibilizando la manera tan dicotómica de ser de la imagen-spam. También se revelarán los estereotipos que ella persigue y al mismo tiempo su deseo de rechazar su propio estereotipo, para cuestionar la manera como las compañías de datos y las plataformas digitales hacen un borrado permanente de estas imágenes-spam.

\section{Palabras clave}

Internet; entornos digitales; imagen-spam; visualidad

\section{The latent desire of the spam-image}

\begin{abstract}
In contemporary digital culture, the exponential increase of images in digital environments is providing an overwhelming experience in all fields covered by the internet, whether ultimately in physical or digital spaces. This is why our approach is to analyze the places and trajectories of spam-images and their own latent desire, highlighting the dichotomous way of being of the spam-image. The stereotypes that this image pursues will be revealed, as well as its desire to reject its own stereotype, to question the way data companies and digital platforms permanently erase these spam-images.
\end{abstract}

\section{Keywords}

Internet; digital environments; spam-image; visuality

\section{Le désir latent de l'image-spam}

\section{Résumé}

Dans la culture numérique contemporaine, l'augmentation exponentielle des images dans les environnements numériques offre une expérience bouleversante dans tous les domaines couverts par la connectivité d'Internet, que ce soit dans des espaces physiques ou numériques. C'est pourquoi notre démarche est d'analyser les lieux et trajectoires des images-spam et leur désir latent, rendant visible la manière d'être dichotomique de l'image-spam. Les stéréotypes que poursuit cette image seront dévoilés, ainsi que sa volonté de rejeter son propre stéréotype, de questionner la manière dont les entreprises de données et les plateformes numériques effacent définitivement ces images-spam.

\section{Mots clés}

Connectivité ; environnements numériques ; image-spam ; visualité

\section{O Desejo latente da imagem-spam}

\section{Resumo}

$\mathrm{Na}$ cultura digital contemporânea o aumento exponencial das imagens nos ambientes digitais está proporcionando uma experiência avassaladora em todos os campos que oferece a conectividade de Internet, sejam em espaços físicos ou digitais. É por isso que, o enfoque é analisar os lugares e trajetórias que têm as imagens-spam e seu desejo latente. Por conseguinte, este artigo se ocupa em visibilizar a maneira tão dicotômica de ser da imagem-spam, mostrando 
os estereótipos que persegue e ao mesmo tempo seu desejo de negar seu próprio estereótipo, questionando a maneira como as companhias de dados e as plataformas digitais fazem um apagamento permanente de imagens-spam.

\section{Palavras chave}

Conectividade de Internet; ambientes digitais; imagem-spam; visualidade

\section{Maillallachiska}

Kunauramanda kausapi kawachikuna llapa ruraikuna, churaspa sugkuna kawangapa ima paikuna kawachingapa muraska chi nispakatichinkuna imasa kausaikuna, chasak pakaskata munanakuna kawachingapa, chagpipi, pakichispa chillatata kawachingapa, tukuikunakawangapa nispa tapuchiriku imasami rurankunakaikuna sakingapa sugrata nispa utka anchuchingapa.

\section{Rimangapa Ministidukuna}

Tukuikuna iachangapa ministiska; kawachinaku ruraikuna; ruraikuna kawachikuna; kawai 


\section{Introducción}

El deseo latente de la imagen-spam muestra como en la cultura digital contemporánea una parte de la imagen-spam define a los seres humanos como perfectibles, mejorables digitalmente y deseantes de la manipulación y edición en un afán de desear, ser imágenes editables o réplicas photoshopeadas. De las múltiples plataformas digitales que han ayudado a incrementar estos deseos han sido las compañías de datos, donde, en las redes sociales se evidencia el racismo, la xenofobia y la aporofobia (Prada. 2018) estas tres últimas palabras como las patologías visuales de nuestro tiempo.

Es así, que este artículo está estructurada bajo preguntas que se dirigen a entender el deseo latente de la imagen-spam, teniendo la necesidad de responder y visibilizar las problemáticas de una parte de la imagen digital actual, que es, la imagen-spam y sustentar con ello la habilidad dicotómica que tiene la imagen-spam para desear los estereotipos implantados y, por otro lado, la habilidad para rechazarlos como vía de escape.

\section{Agentes dobles: estereotipos de la imagen- spam}

Toda la conectividad de Internet ha supuesto una revolución tecnológica que ha traído una nueva manera de sometimiento y una desaparición forzada ${ }^{1}$ en los países de extracción de minerales, es por esto, que no se puede dejar de lado la imagen-spam, porque "el spam constituye la mayor parte de la escritura digital" (Steyerl. 2018, p. 145), e Internet ha sido la plataforma que ha engendrado spam digital y spam físico, por causa de la desigualdad en todas las esferas de la conectividad digital.

\footnotetext{
1 La desaparición forzada existe en la contemporaneidad de la era digital, véase la cita textual de Hito Steyerl sobre este tema: La era de la revolución digital se corresponde con la de la desaparición forzada y el asesinato masivo en la antigua Yugoslavia, Ruanda, Chechenia, Argelia, Irak, Turquía y partes de Guatemala, por enumerar solo unos pocos casos. Los investigadores coinciden en que el conflicto de la República Democrática del Congo, que causo uno 2,5 millones de víctimas de guerra entre 1998 y 2008, tuvo como una de sus causas directas la exigencia de materias primas como el coltán por parte de las Information Technology Industries [Industrias de Tecnología de la Información]. Se estima en 18.000 el número de personas migradas que han muerto en el intento de llegar a Europa desde 1990. Steyerl, Hito, Los condenados de la pantalla. Editorial Caja Negra, 2014. p. 179.
}

"El spam es una de las muchas materias oscuras del mundo digital" (Steyerl. 2014, p. 168), y eso implica en cuestión, analizar la cantidad de imágenes-spam que las comunicaciones y la conectividad tienen en el entorno digital.

Un estudio llevado a cabo por la sociedad Incapsula — proveedora de servidores seguros-, que se publicó en febrero de 2012, concluyó que el 51\% del conjunto del tráfico de Internet era generado por agentes no humanos: programas de hacking, envíos automáticos de spam y otros procedimientos automatizados; el 20\% de este 51\% fue juzgado "neutro", mientras que la mayoría del trafico (un 31\%) era potencialmente maliciosa. Esta investigación se basa en el análisis de datos recolectados a partir de un millar de sitios que utilizan los servicios de Incapsula (Sadin. 2017, p. 31).

Es decir, en la cultura digital contemporánea la imagen-spam o como lo plantea Steyerl (2018) la imagen-basura, constituye el mayor porcentaje de información que circula alrededor del planeta tierra, e inclusive, se desplaza por el espacio viajando a la velocidad de la luz, permitiéndose el protagonismo de ser la que mayor producción tiene entre correos electrónicos, donde se multiplican cada vez más "contenidos de consejos para compartir o anuncios de viagra" (Evening Standard, 2012, párr. 1). En el análisis del artículo "'Image spam' could bring the Internet to a standstill" (Evening Standard, 2012), demuestran que el número de correos no deseados enviados diariamente rondaban en 2010 los 250.000 millones y aunque las cifras siguen aumentando, es la imagen-spam la única que podría llegar a "paralizar Internet" (Evening Standard, 2012).

Lo que puede paralizar las imágenes-spam no sólo es Internet con el incremento de correos e imágenes basura, sino, los contenidos que circulan compitiendo por la atención de cada ser humano. Si se observa el contenido de las imágenes-spam, se ve que generalmente corresponden a:

Anuncios de productos farmacéuticos, artículos de imitación, embellecimientos corporales, agrandamientos peneanos y diplomas universitarios [Fig. 1]. De acuerdo con las imágenes que disemina el spam, la humanidad consistiría en personas diplomadas escasas de ropa con sonrisas joviales mejoradas por aparatos de ortodoncia. La imagen-spam quiere mostrar gente mejorable, potencialmente "sin defectos", la imagen-spam 

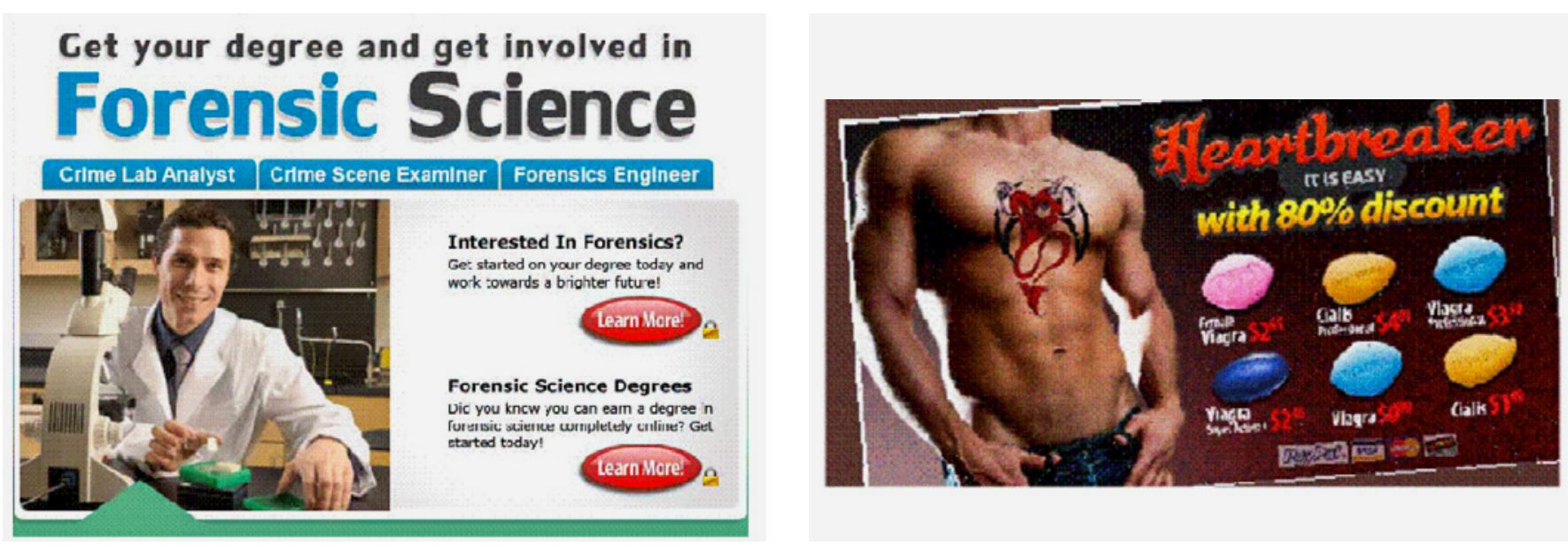

Figura 1. (Steyerl, 2012). The Spam of the Earth: Withdrawal from Representation. E-flux. La imagen de la izquierda un ejemplo de escolarización de publicidad no deseada, la imagen de la derecha es un ejemplo de venta de productos para mejora de la actividad sexual como publicidad spam.

puede decirnos mucho acerca de los seres humanos "ideales", pero no mostrándonos verdaderos humanos (Steyerl. 2014, p. 168).

Es verdad, que, como materia oscura del mundo digital, la imagen-spam nació con un principio, expandir los estereotipos, su más oscura intención radica en ese lugar que ha cobrado vida por su capacidad de idealización y atracción visual.

Hay muchas razones para usar imágenes en el correo electrónico, desde simplemente hacer que el correo electrónico sea más interesante o agregar una apariencia de profesionalismo hasta intentar evadir los filtros y firmas de spam basados en texto, es tan importante que el spam sea en imágenes porque las imágenes remotas también permiten a los spammers usar herramientas de monitoreo web para rastrear la efectividad de sus propias ejecuciones de spam. Cuando se descarga la imagen, el spammer puede registrar la misma información sobre la computadora de la víctima como un sitio web legítimo, incluida la dirección IP, el cliente de correo electrónico utilizado... (Nisbet, 2010, párr. 2).

Por consiguiente, el contenido de las imágenes-spam está relacionado con la imagen "photoshopeada" (Steyerl, 2014. p. 169), que, de manera ilusoria, una vez sometida a un cuidadoso proceso de edición, pretende mejorar nuestra calidad de vida, promedio académico, aspecto físico, entre otros. La imagen-spam está diseñada para aquellos que no cumplen con esos estándares, y por lo general son encaminados para perfeccionar la apariencia corporal, por eso, toda la publicidad basura va dirigida a las personas que no se parecen a esos anuncios, pero, que quieren llegar a esa apariencia.

La imagen-spam es una imagen estereotipo, W. E. B. Du Bois llamó al estereotipo un "velo", que se interpone entre las personas, más tarde, lo llamaría W. J. T. Mitchell un caso especialmente importante de la imagen viva, es decir, -en cuanto a esto, a las imágenes no deseadas-, la imagen-spam mantiene una máscara, y el que decide llevarla la convierte en una imagen viva* (Prada. 2018, p. 96) porque estas imágenes muestran un ideal del ser humano que no es y que no lo representa, "todos sabemos que los estereotipos son malos, que son imágenes falsas que nos previenen de ver la verdad a las otras personas" (Mitchell. 2017, p. 369). Sin embargo, la imagen-spam maneja el estereotipo como una forma de activar los prejuicios ocultándose como un patrón de imagen ideal.

El artista británico Richard Hamilton ya ilustró en 1956 una imagen estereotipo de lo que representaba mediáticamente una familia inglesa promedio de los años 50 , con la obra "¿Pero qué hace a los hogares de hoy tan diferentes, tan atractivos?" [Fig. 2]. El artista muestra por medio de la técnica del collage cómo los hogares ingleses se construían así mismos tomando como modelo imágenes de todo tipo, que circulaban dentro de la publicidad obsesiva de la época. Hamilton nos muestra un hogar remezclado, que no está tan lejano de lo que hoy vemos en las imágenes-spam. La obra de Hamilton es una imagen compuesta de pedazos de imágenes que expresa el ideal de familia con todas las contradicciones que hay en ello, su narcisismo, el perfeccionamiento 


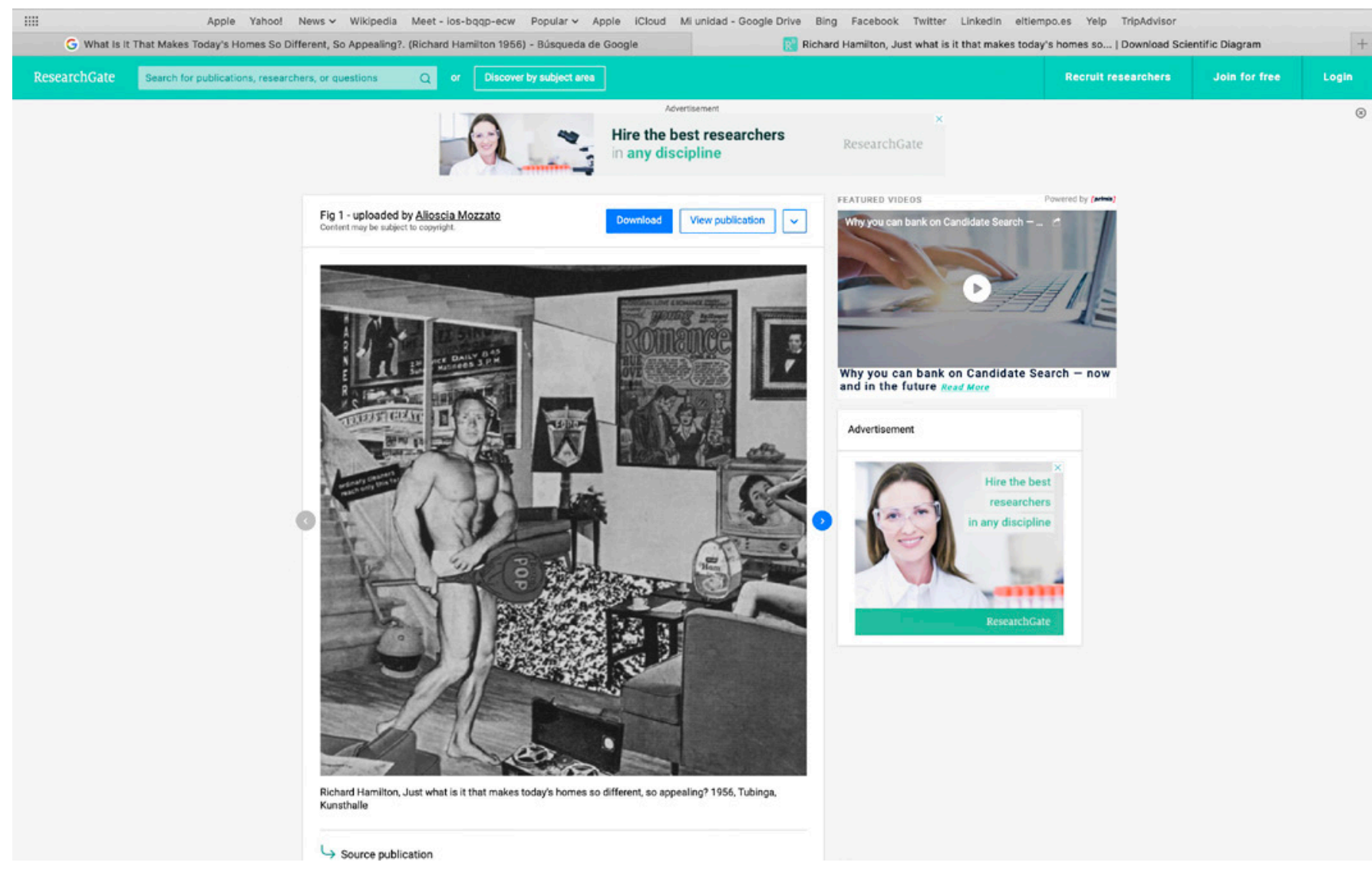

Figura 2. (Richard Hamilton 1956) Just What Is It That Makes Today's Homes So Different, So Appealing?.

corporal, un deseo de autonomía, de independencia y un estatus social que se gana con la última tecnología para el hogar.

* La cursiva es mía para redirigir una interpretación que hace Martín Prada frente al concepto de imagen viva del escritor W. J. T. Mitchell. Prada interpreta: las imágenes en la red poseen una enorme motilidad, una inmensa capacidad para moverse por sí mismas, una especie de aptitud para vivir por su cuenta, para replicarse a la manera de un virus en mutación continua, sometiéndose a infinidad de mecanismos y prácticas de transformación. Prada, Juan Martín, El ver y las imágenes en el tiempo de Internet, Akal/Estudios visuales, 2018. p. 96.

No obstante, con esto se sabe que "los estereotipos son formas de juicio falsas y corruptas" (Mitchell. 2017, p. 380) en esto último, si se traslada a la situación actual, la compañía de seguridad cibernética Symantec ha estado luchando actualmente contra el spam que se incrementa cada día por la situación generada por la pandemia del COVID-19, en un artículo titulado Text-Based COVID-19 Spam Wants Your Information, Money donde muestran [Img. 3] las campañas spam relacionadas con el COVID-19 y cómo la compañía advierte los peligros de estafas vía spam:

Estos correos electrónicos no contienen ningún adjunto malicioso y, en cambio, se basan en lo que está escrito en el correo electrónico para engañar a los usuarios para que entreguen información o dinero.

Estas campañas de spam basadas en texto incluyen los siguientes tipos de estafas: Correos electrónicos de propuestas comerciales de pequeñas y medianas fábricas que ofrecen vender equipos médicos como mascarillas quirúrgicas, kits de equipos de protección personal (EPP), desinfectantes y ventiladores. Correos electrónicos de donantes generosos que afirman estar regalando grandes sumas de dinero a los necesitados. Correos electrónicos de estafa de lotería. Correos electrónicos que solicitan donaciones de personas a través de criptomonedas o tarjetas de regalo (Thaware, 2020, párr 2-4).

Estas empresas de seguridad cibernética que tratan de ubicar el spam para detener los engaños y actos 


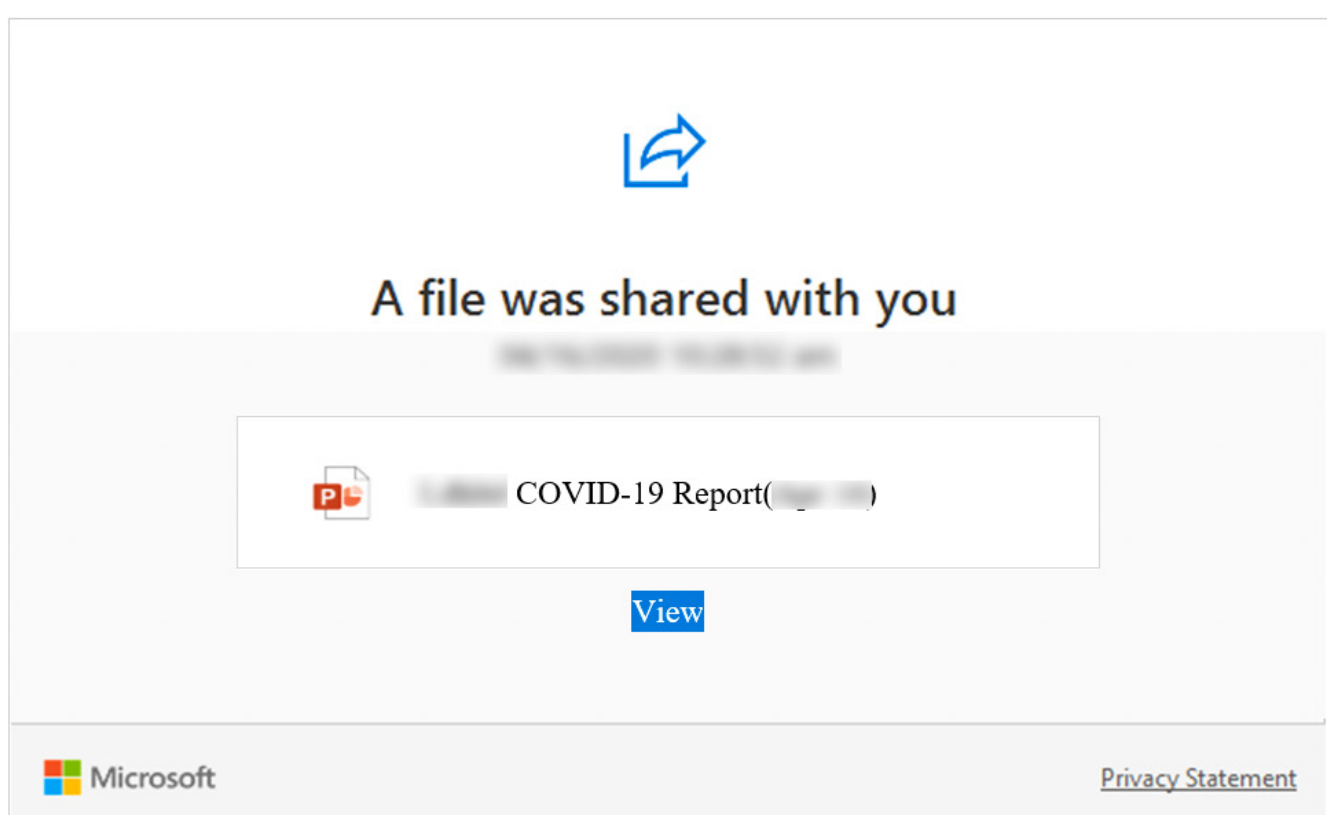

Figura 3. (Thaware, 2020) Symantec, Text-Based COVID-19 Spam Wants Your Information, Money.

fraudulentos en la red son sólo una parte del ecosistema de regulación anti-spam, sin embargo, en las plataformas de las redes sociales más populares, manejan un sistema de detección automática de imágenes, que son, "los verificadores de contenido" (DW, 2020), que revisan y borran contenido que pueda ir en contra de las normas de las plataformas digitales, "por una fuerza de trabajo global subcontratada en Turquía, Filipinas, Marruecos, México e India, personas que trabajan desde su casa y ganan alrededor de cuatro dólares por hora. Estos trabajadores son contratados para distinguir entre partes del cuerpo aceptables (la cara) e inaceptables (el culo)" (Steyerl. 2018, p. 52).

En el territorio de la imagen-spam estas son indeterminables por su alto contenido estereotipado, y por eso, no está claro "donde" esta la imagen-spam por lo difícil que es mapearla, encontrarla, y porque lo que representa como estereotipo, que es, el cuerpo humano "retocado, redireccionado, grabado, borrados, remodelados, o reemplazados en nuestra propia imagen" (Steyerl. 2018, p. 51).

Con esto no se entraría en polémicas de qué es lo que se debe o no ver en las redes sociales, la importancia radica en que las directrices de regulación de imágenes de estas plataformas marcan patologías visuales como el racismo, la xenofobia y la aporofobia. En estos estereotipos es donde está la imagen-spam y por causa de esas regulaciones se incrementan.

La cara negra (junto con la "cara amarilla" y el antisemitismo, los prejuicios contra los "rednecks", los árabes y los otros Otros) se compone de un repertorio de imágenes que parecen absolutamente despreciables y merecedoras de destrucción, y además también actúan de forma muy similar a un virus que resiste todos los esfuerzos de erradicación o inmunización (Mitchell. 2017, p. 371).

Lo más lógico sería mantener la regulación y la prohibición de estas imágenes-spam merecedoras de destrucción, sin embargo, el planteamiento de W. J. T. Mitchell en el ensayo "Vivir el color. Raza, estereotipo y animación en Blamboozled de Spike Lee", demuestra qué debe hacerse con las imágenes estereotipo, podríamos simplemente prohibirlas y reemplazarlas por imágenes benignas, políticamente correctas y positivas ...este tipo de estrategia directa de iconoclasia crítica generalmente sólo consigue inyectar más vida y poder a la imagen menospreciada (Mitchell. 2017, p. 372). 
Esto quiere decir, que prohibirlas solo consigue expandirlas, y la única manera sería no tratar de destruirlas sino de mirar de frente a los estereotipos. En un caso particular W. J. T. Mitchell ejemplifica lo anterior con el film "Blamboozled" del director Spike Lee del año 2000, donde el protagonista negro, tiene la cara pintada de negro [Img. 4] para mostrar como en el pasado actores blancos se pintaban la cara de negro para representar a los negros en el cine estadounidense.

Esta es una forma autoconsciente de ver "las imágenes raciales, y del modo como circulan en los medios y en la vida cotidiana" (Mitchell. 2017, p. 375). Según Spike Lee está es la forma en la que se pueden confrontar los estereotipos hacia los afroamericanos, confrontar al estereotipo con su propia imagen.

Siguiendo con esto, una reflexión fundamental que hace Steyerl sobre los estereotipos que conforman la imagen-spam y su efecto mimético —el de querer parecerse a estas imágenes - es confrontarla con su propio estereotipo, la imagen-spam de cuerpos perfectos e ideales ha generado por largos años un deseo en las personas por querer convertirse en los productos representados de esa publicidad spam, de eso modo, se pregunta Steyerl "¿y si la gente real —ni perfecta ni caliente- no fuera excluida de la publicidad spam a consecuencia de sus supuestas deficiencias, sino que hubiera decidido desertar de este tipo de retrato?" (Steyerl. 2014, p. 171). Eso significa que las imágenes-spam han perdido el sentido que les proporcionaba vida, porque una pequeña parte de personas han desistido de ese tipo de representación spam, que quiere por todos los medios homogenizar los gestos, los hábitos y los afectos.

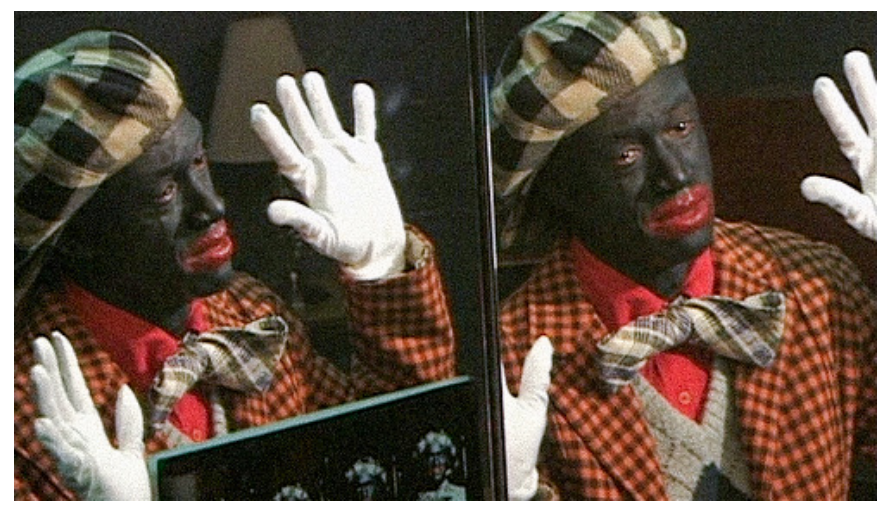

Figura 4. (Spike Lee, 2000) Fotograma del film Blamboozled.

\section{Seres deseantes hacia la destrucción de la pantalla}

La multinacional japonesa NEC "llegó al mercado colombiano con el objetivo de ofrecer soluciones de autenticación con aplicaciones de seguridad (Detección de individuos no deseados, monitoreo de área segura, Control de acceso) y comerciales (Identificación VIP, Monitoreo de filas, Inteligencia de negocios), un tema vital para Bogotá en materia de seguridad" (Nuevo siglo, 2016, párr. 2), esta implementación no fue exitosa en las instalaciones de Transmilenio de la cuidad de Bogotá porque "quien instaló las cámaras olvidó el pequeño detalle de que se necesita una base de datos con fotos e información ciudadana para cotejar lo que las cámaras captan"(Montes, 2020, párr. 5)

Frente a este percance unos años después, en la ciudad de Medellín exactamente en el año 2016 se instalaron las cámaras de reconocimiento facial en el estadio Atanasio Girardot, para "controlar los conflictos de las barras bravas de los equipos de fútbol locales" (NEC. 2017) y, en el año 2020 Colombia es tambien la que lidera la lista de países latinoamericanos en ser "el primer país" (Grupo Éxito, 2020, párr. 2) en implementar el pago de productos con reconocimiento facial.

Aquí se puede ver cómo "cada rincón de nuestras ciudades está mapeado como el probable sitio de un crimen" (Steyerl. 2018, p. 93), siendo el objetivo de la multinacional japonesa NEC junto con los gobiernos, detectar individuos no deseados. ¿Así es cómo ven al ser humano los gobiernos? ¿cómo individuos no deseados?. Si, y para controlarlos en lugares de conflicto han incrementado la vigilancia por medio de los dispositivos tecnológicos como herramienta para capturarlos.

Las aplicaciones de seguridad han cambiado el objetivo de captura, si las agencias cibernéticas han tratado de detener los correos spam por causas corruptas, ahora, las aplicaciones de seguridad ayudan a las compañías, los gobiernos y militares a la "detección de individuos no deseados" (Steyerl. 2018, p. 93), no sólo por las cámaras de reconocimiento facial que les ayuda a capturarlos sino también por "cámaras de teléfonos móviles adivinas y vistas aéreas desde drones pinchados" (Steyerl. 2018, p. 93). Esta herramienta les ha dado el derecho a mirar a los seres humanos en lugares de conflicto 0 , a los que van más allá de esos lugares, porque también visualizan la vida cotidiana de cada persona. 


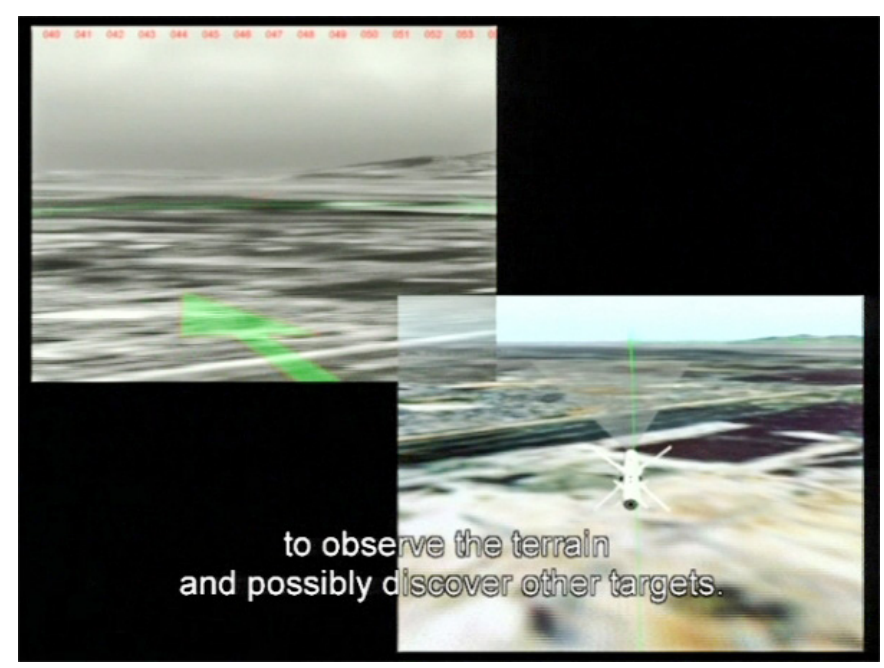

Figura 5. (Loop) (Harun Faroki, 2003) Serie: Auge/Maschine II, 2-channel installation, color, sound. $25 \mathrm{~m}$.

Un símil que utiliza Steyerl para explicar cómo una cámara con objetivo militar, son los miles de millones de cámaras que se incorporan en nuestra vida cotidiana, es a partir de la obra [Fig. 5] del cineasta Harun Faroki que acuñó el término:

Cámara suicida ejemplificándolo con la obra titulada Auge/Maschine donde muestra una serie de cámaras montadas sobre las puntas de los misiles en la Primera Guerra del Golfo. La cámara transmitía en vivo hasta su explosión. Pero, al contrario de lo que podría esperarse, la cámara no fue destruida durante esta operación. En cambio, estallo en miles de millones de cámaras pequeñas, minúsculos lentes incorporados en los teléfonos móviles. La cámara del misil explotó en esquirlas que penetraron en la vida de las personas, sus sentimientos e identidades, sobrevolando sus ideas y sus cuentas bancarias (Steyerl. 2018, p. 95).

Las miles de millones de cámaras pequeñas han impedido que los visualizados/los spams contemporáneos, se les niegue sus derechos y no puedan hacer resistencia de ningún tipo, hay que mirar que no sólo las cámaras de reconocimiento facial o drones que están en las calles, son el instrumento para los que visualizan, también utilizan las cámaras de los teléfonos móviles. "Existen todo tipo de sistemas que pueden encender o apagar nuestras cámaras remotamente: las empresas, los gobiernos y los militares. Pueden ser desactivadas en ciertos lugares: se podrían, por ejemplo, bloquear sus funciones de registro cerca de protestas 0 , al contrario, transmitir todo lo que ven en ese entorno" (Steyerl. 2018, p. 50).
Si bien, una parte de las imágenes-spam son los seres humanos que han rechazado la publicidad de seres ideales, para convertirse en un pequeño sector de la población que evita ser representado en fotografías y cámaras de vigilancia que les persigue de forma persistente, "la gente ha empezado a rechazar - de manera activa y pasiva - el ser vigilada, grabada, identificada, fotografiada, escaneada y registrada" (Steyerl. 2018, p. 171).

Ese rechazo a ser capturados por cámaras de todo tipo tiene que ver con zonas de conflicto, en el caso de las barras bravas de Medellín que se agrupan en el estadio Atanasio Girardot, "en lugares de extrema emergencia y peligro o en el flujo constate de emisiones en vivo desde zonas de conflicto alrededor del mundo" (Steyerl. 2014, p. 172).

El ser fotografiado por cámaras significa ahora desaparecer, sí antes el concepto fotográfico era representar, en la cultura contemporánea digital lo fotográfico es una herramienta de desaparición debido al régimen de control que se ejerce sobre los individuos.

El destello de los flashes fotográficos convierte a la gente en víctimas, en celebridades o en ambas cosas. Mientras damos nuestros datos en cajeros automáticos, cajas registradoras y otros puntos de control, mientras nuestros teléfonos celulares revelan nuestros mínimos movimientos y nuestras instantáneas son etiquetadas con coordenadas GPS, acabamos, no exactamente divirtiéndonos hasta la muerte, sino más bien representados hasta hacernos pedazos (Steyerl. 2014, p. 174).

Un proyecto que estuvo pensado para evitar la detección de un individuo no deseado fue la aplicación iSee Manhattan [Fig. 6], "que ofreció entre los años 1998 2002 la oportunidad de crear rutas, llamadas carreteras menos vigilantes, que permitían a las personas "caminar por sus ciudades sin temor a ser" registradas "por monitores de seguridad no regulados" " (Institude for Applied Autonmy, 1998).

El objetivo de este proyecto era una declaración al derecho a la privacidad y es evidente la llamada que hace a salir del radar, con razones legitimas para evadir ser visto por las cámaras de Manhattan, "la tendencia demostrada de los operadores de Circuito Cerrado de Televisión (CCTV) de señalar a las minorías étnicas para su observación y enfocarse voyeurísticamente en los senos y las nalgas de las mujeres proporciona a la mayoría de 


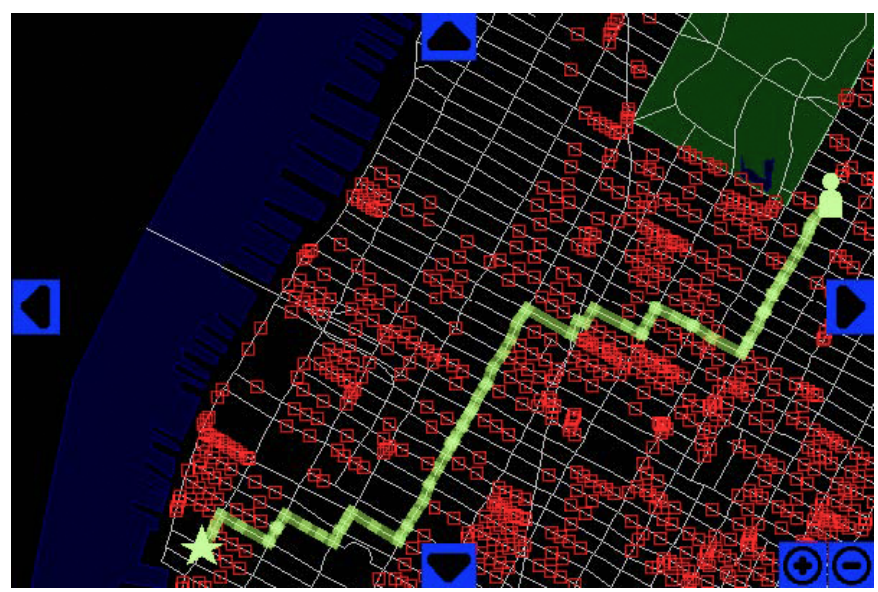

Figura 6. (Institude for Applied Autonmy, NYC Surveillance camera Project. 1998 - 2002). iSee Manhattan.

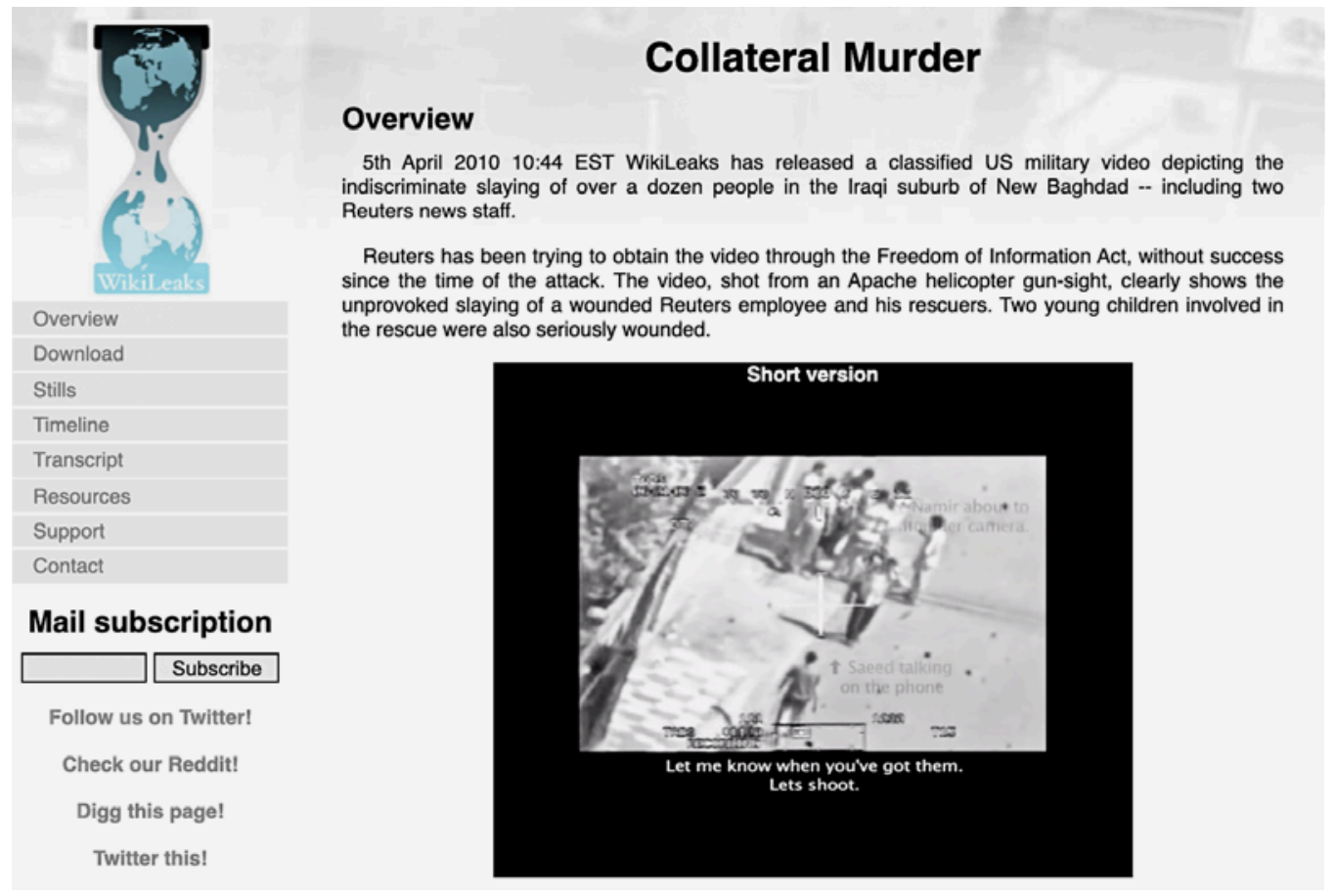

Figura 7. (WikiLeaks, 2010) Collateral murder.

la población amplias razones legítimas para evitar las cámaras de vigilancia pública" (Baard, 2001, párr. 7).

No es sencillo escapar de las 2400 cámaras identificadas entre los años 1998-2002 en la ciudad de Manhattan, sin embargo, hay una intersección entre el objetivo de esta aplicación y una situación vigente que ilustra la detección de un individuo no deseado que es el caso del programador, periodista, activista de Internet y fundador de WikiLeaks Julián Assange que actualmente lleva un proceso ante la justicia, se le acusa de 18 cargos.
Filtrar 400.000 documentos sobre la guerra de Irak, 90.000 sobre la guerra de Afganistán y 250.000 del Departamento de Estado de Estados Unidos. Entre ellos destaca 'Asesinato Colateral' [Fig. 7]. Un vídeo que mostraba el bombardeo de población civil cerca de Bagdad, Irak y el 'Cablegate', relacionado con los maltratos y torturas llevadas a cabo en la prisión de Guantánamo (Redacción Barcelona, 2020, párr. 5).

El trabajo que ha hecho Julián Assange en WikiLeaks replanteó las normas profesionales de producción de verdad en el periodismo revelando documentos que lograron sacudir el entorno de especulación y rumor 
que mantenía el periodismo en los momentos en que la plataforma WikiLeaks mantenía un alto grado de actualización de documentos para dar a conocer lo que los gobiernos ocultaron.

Con WikiLeaks se muestra el problema sobre toda la información que falta ver y sobre lo que representa Assange para las empresas, los gobiernos y los militares. Un hombre que reclama el derecho a mirar, el derecho a existir, un hombre que en palabras de Mirzoeff está contravisualizando la visualidad, es decir, Assange hizo una ruptura con ese proyecto de visión que es la visualidad y se ha enfrentado a la dominación y desigualdad de la información para lograr la emancipación del modo en que solíamos mirar las imágenes, sin embargo, esto le ha costado la privación de su libertad hasta el punto que su imagen en los medios de comunicación ha estado ausente e invisible.

Dentro de todo este escenario cabe preguntar ¿qué desean las imágenes no deseadas? Una manera de analizar el deseo de las imágenes se encuentra en la escena de la película Videodrome del director David Cronenberg [Fig. 8]. En la secuencia se puede ver cómo el protagonista del film Max Wren interpretado por James Woods está frente a la pantalla de televisión con los brazos extendidos tratando de abrazar el aparato televisivo, para luego, intentar adentrarse en la pantalla debido a que se siente atraído por la imagen que ésta emite, unos labios que le dicen "ven a mí, ven a Nicki".
Este es un ejemplo que nos muestra W. J. T. Mitchell en su libro ¿Qué quieren las imágenes? Donde argumenta que, la pregunta por la imagen "no sólo es, qué pretenden decir o hacer, sino qué quieren —qué afirmación hacen sobre nosotros y cómo respondemos ante ellas-"(Mitchell. 2017, p. 15). ¿Quieren atraparnos? ¿quieren seducirnos? O por el contrario quieren devorarnos como en la secuencia del film Videodrome.

Es importante el análisis del deseo de las imágenes que hace Cronenberg porque plantea cómo el sujeto que observa está en riesgo de ser tragado por la pantalla al haber mirado la imagen que esta proyecta y a su vez como la pantalla es situada como proyección y cumplimiento del deseo del protagonista. Sin embargo, Douglas Phillips en su ensayo, ¿Puede el deseo continuar sin un cuerpo? Intercambio pornográfico y la muerte del sol, analiza el deseo y la pantalla desde la perspectiva de Lyotard que no dista de estar alejada de la hipótesis de Cronenberg, diciendo:

El sujeto que desea invierte sus intensidades pulsionales en la pantalla, en una búsqueda de satisfacción, y este deseo se captura y se cumple en la pantalla... El deseo, debe entenderse, se representa en la pantalla: es uno y lo mismo que la pantalla, es a la vez la estructura de la pantalla y su tema (Phillips, 2009, párr. 31).

Si se traslada ese deseo a las imágenes-spam, ellas nos invitarían a resistir el ser tragados por la pantalla

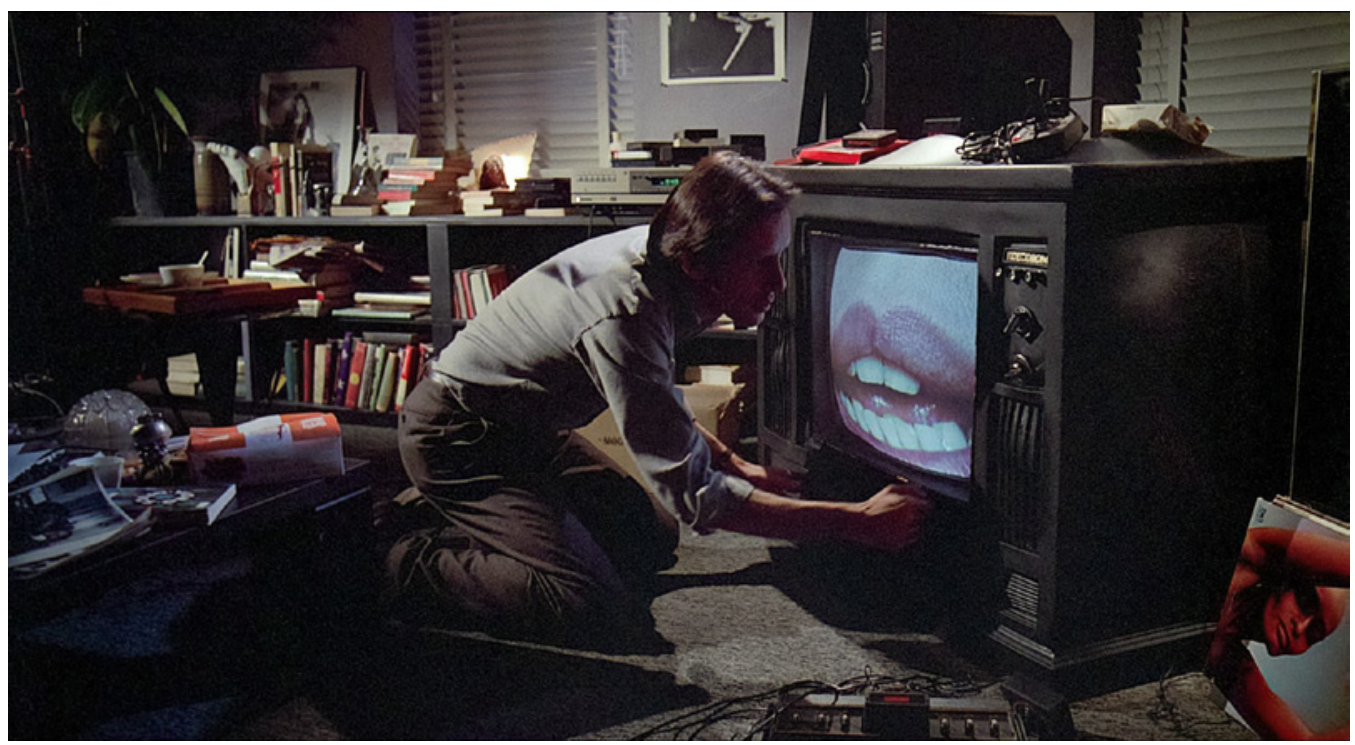

Figura 8. (David Cronenberg, 1983) Videodrome. 
televisiva — como al protagonista de Videodrome- y por las miles de pantallas que rodean la vida cotidiana de cada ser humano. las imágenes-spam quieren evitar el radar, y quieren no ser consumidas por las pantallas.

\section{Conclusiones}

El deseo latente de la imagen-spam concluye que hay dos formas de ser de la imagen-spam la primera, una imagen sustituta que ha llenado los vacíos que tienen los entornos digitales a causa del monopolio de la información, esa parte de la imagen-spam ha desatado patologías visuales en la era de la cultura digital contemporánea que han engendrado los estereotipos, y quiere llegar a ser perfectible y cada vez mejorable tomando como accionar el incremento del racismo, la aporofobia en las plataformas digitales.

Sin embargo, la otra parte de la imagen-spam es un doble agente digital que se cuestiona y desea huir de los estereotipos confrontando los estereotipos, no quiere ser ni perfectible ni mejorable, pero, desea reclamar su papel como testigo histórico, desea cuestionar los métodos de filtrado que tienen las redes sociales y los gobiernos, su politica de censura, privación y limpieza digital que descontextualizan los procesos historicos actuales.

Con el trabajo específico de los moderadores de contenido se ven los métodos de la limpieza digital que ejercen sobre las imágenes-spam. Ellos han causado el borrado de situaciones elementales para el contexto y la historia en curso, porque los moderadores de contenido no disponen de contexto y herramientas culturales e históricas para saber que dejar en la red o no, porque las directrices de Facebook sólo les indica borrar elementos sin tener ninguna lectura ni ninguna referencia cultural y eso conlleva a un drastico borrado de imágenes-spam generando que las plataformas digitales instiguen los conflictos sociales y políticos.

En ese sentido, hay una afirmación de la importancia que la imagen digital tiene en esta cultura hiperconectada y es lo que dice la historiadora Ariella Azoulay (2019), refiriendose a que se puede saquear la vida de las personas a través de imágenes, y, si se extrapola esa afirmación a la cultura actual que consume imágenes-spam de todo tipo y que al mismo tiempo es perseguida para ser borrada, censurada y privada, se puede, parafraseando a Steyerl (2014) analizar la imagen-spam como un legado histórico de nuestro tiempo, es decir, empezar a pensar que si la imagen-spam es el material que abarca el mayor espacio en informacion en nuestras comunicaciones, probablemente podríamos empezar a "imaginar una reconstrucción de la humanidad hecha a partir de esta basura digital" (Steyerl. 2014, p.168).

Eso significa que la historia que se puede estar contando inadvertidamente de lo que es el humano hoy en dia, es una historia en imágenes-spam y si se proyecta ese retrato de nuestro tiempo, "entonces miramos hacia el futuro, incapaces de ver o incluso pensar qué nos deparará. Lo que sí sabemos es que la tecnología se está complejizando radicalmente y está siendo llevada a tal complejidad por el deseo: el deseo de más, ahora, más rápido, más libre. Esta es la única forma en que podemos pensar en avanzar y preservar el rastro de la existencia humana y el potencial del pensamiento" (Phillips, 2009, párr. 31). Este es el deseo latente de la imagen-spam.

\section{Referencias}

Àngels Barcelona. (2014). Harun Faroki.

https://tinyurl.com/2325fnh7

Azoulay, Ariella, (2012), The civil contract of photography, Zone Books.

Baard, E. Routes of least surveillance. Wire. https://tinyurl.com/ys7xh56f

Bellamy, J. (2012) The Conversations: Bamboozled. Slantmagazine. https://tinyurl.com/4sbb359d

Bernal, M. (27 de marzo de 2019). Ariella Azoulay: "Se puede saquear la vida de las personas a través de las imágenes". elPeriódico. https://tinyurl.com/3tn2bnts

Cinéma, Questionnaire (2019, noviembre 8) Le Questionnaire Libé(rez)-Soderbergh [Consulta: 2 junio, 2020]. Disponible en https://tinyurl.com/ee7rmj9s

DW Documental (2020, junio 14) Los limpiadores digitales - En las sombras de la red Parte 1 [Archivo de video]. Recuperado de https://tinyurl.com/sdnuffns

DW Documental (2020, junio 14) Los limpiadores digitales - En las sombras de la red Parte 2 [Archivo de video]. Recuperado de https://tinyurl.com/xek65rav 
Farocki, Harun, (2013), Desconfiar de las imágenes. Argentina, Editorial Caja Negra.

Grupo éxito. (2020) Colombia, primer país de América Latina en implementar el pago con reconocimiento facial. Grupo éxito.https://tinyurl.com/tmcafjub

London Evening Standard (2007). El 'spam de imágenes' podría detener Internet. EveningStandard. https://tinyurl.com/h82futuy

Martínez Luna, Sergio, (2019), Cultura visual: la pregunta por la imagen, Sans soleil ediciones.

Mirzoeff, Nicholas, (2003) Una introducción a la cultura visual, España, Ediciones Paidós Ibérica. S.A.

Mirzoeff, Nicholas, (2016) El derecho a mirar, IC Revista Científica de Información y Comunicación, 13, pp. 29 - 65. https://tinyurl.com/n9zjncaw

Mitchell, W. J. T. ¿Qué quieren las imágenes?, (2017) Sans Soleil ediciones.

Montes, A. (2020) El reconocimiento facial no es una buena opción. Semana. https://tinyurl.com/4j9e4spc

NEC Corporation, (2017) Sistema integrado de vigilancia y seguridad para estadio Atanasio Girardot-Medellín. https://tinyurl.com/bht63kzz

Nisbet, M. (2010) Image Spam. Broadcom. https://tinyurl.com/z5vh7jr7

Parikka, J y D. Sampson, T, (2009) The Spam Book: On Viruses, Porn and Other Anomalies From the Dark Side of Digital Culture.

Phillips, D. (S.f.) Can Desire Go On Without A Body?

Culture Machine, InterZone. https://tinyurl.com/kp99e7pw

Prada, Juan Martín, (2018), El ver y las imágenes en el tiempo de internet, Akal/estudios visuales.

Redacción Barcelona. (2020) Comienza el juicio para extraditar a Julián Assange a Estados Unidos.

La vanguardia. https://tinyurl.com/xwdhcs

Rus, Olvido, (2014, octubre 20) ¿Qué hace a Richard Hamilton tan diferente, tan atractivo? [Consulta: 27 mayo 2020]. Disponible en: https://tinyurl.com/5x9sefab
Sadin, Éric, La humanidad aumentada: La administración digital del mundo, Editorial Caja Negra.

Steyerl, H. (2012). The Spam of the Earth: Withdrawal from Representation. E-flux https://tinyurl.com/ca92z8zb

Steyerl, Hito, (2018), Arte duty free: El arte en la era de la guerra civil planetaria, editorial Caja Negra.

Steyerl, Hito, (2014), Los condenados de la pantalla, Editorial Caja Negra.

S.N., (2016) Bogotá, con cámaras de reconocimiento facial. El nuevo siglo. https://tinyurl.com/frmjx4zd

Thaware, Vijay (2020, mayo 18) Text-Based COVID-19 Spam Wants Your Information, Money [Consulta: 17 mayo, 2020]. Disponible en https://tinyurl.com/5fc8xy2t

WikiLeaks. (s.f.). Collateral murder. https://tinyurl.com/27urmr95

Wikipedia. Spam (alimento). (7 de junio, 2020). Disponible en https://tinyurl.com/jbt7n7uf

Institude for Applied Autonmy, NYC Surveillance camera proyect. (1998). iSee [Aplicación móvil] https://tinyurl.com/a6b95pfh 